\title{
The Hospital-Community-Family-Based Telemedicine (HCFT-AF) Program for Integrative Management of Patients With Atrial Fibrillation: Pilot Feasibility Study
}

Jiang Jiang ${ }^{1 *}$, MA; Xiang Gu ${ }^{2,3^{*}}, \mathrm{MD}, \mathrm{PhD}$; Chen-Di Cheng ${ }^{4 *}$, MA; Hong-Xiao Li ${ }^{2,3 *}$, MD; Xiao-Lin Sun ${ }^{2,3}$, MD; Ruo-Yu Duan ${ }^{1}$, MA; Ye Zhu ${ }^{2,3}$, MD; Lei Sun ${ }^{2,3}$, MA; Fu-Kun Chen ${ }^{2,3}$, MD; Zheng-Yu Bao ${ }^{2,3}$, MD; Yi Zhang ${ }^{2,3}$, MA; Jian-Hua Shen ${ }^{2,3}$, MA

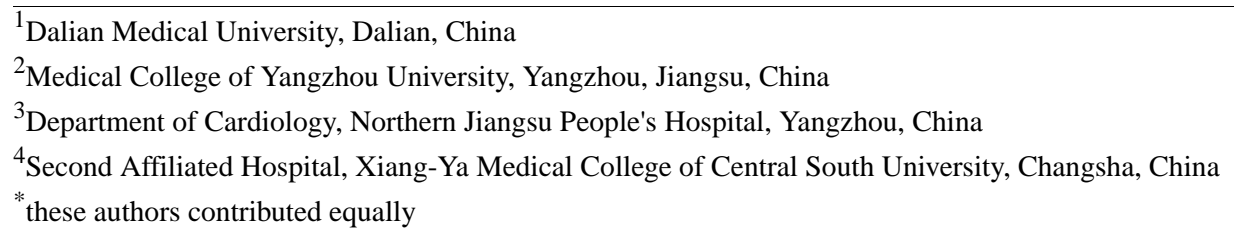

Corresponding Author:

Xiang Gu, MD, PhD

Medical College of Yangzhou University

No. 98, Nantong West Road

Yangzhou, Jiangsu, 225001

China

Phone: 86051487373366

Email: guxiang@yzu.edu.cn

\section{Abstract}

Background: The potential effectiveness of integrated management in further improving the prognosis of patients with atrial fibrillation has been demonstrated; however, the best strategy for implementation remains to be discovered.

Objective: The aim of this study was to ascertain the feasibility of implementing integrated atrial fibrillation care via the Hospital-Community-Family-Based Telemedicine (HCFT-AF) program.

Methods: In this single-arm, pre-post design pilot study, a multidisciplinary teamwork, supported by efficient infrastructures, provided patients with integrated atrial fibrillation care following the Atrial fibrillation Better Care (ABC) pathway. Eligible patients were continuously recruited and followed up for at least 4 months. The patients' drug adherence, and atrial fibrillation-relevant lifestyles and behaviors were assessed at baseline and at 4 months. The acceptability, feasibility, and usability of the HCFT-AF technology devices and engagement with the HCFT-AF program were assessed at 4 months.

Results: A total of 73 patients (mean age, 68.42 years; 52\% male) were enrolled in November 2019 with a median follow up of 132 days (IQR 125-138 days). The patients' drug adherence significantly improved after the 4-month intervention $(P<.001)$. The vast majority $(94 \%, 64 / 68)$ of indicated patients received anticoagulant therapy at 4 months, and none of them received antiplatelet therapy unless there was an additional indication. The atrial fibrillation-relevant lifestyles and behaviors ameliorated to varying degrees at the end of the study. In general, the majority of patients provided good feedback on the HCFT-AF intervention. More than three-quarters $(76 \%, 54 / 71)$ of patients used the software or website more than once a week and accomplished clinic visits as scheduled.

Conclusions: The atrial fibrillation-integrated care model described in this study is associated with improved drug adherence, standardized therapy rate, and lifestyles of patients, which highlights the possibility to better deliver integrated atrial fibrillation management.

Trial Registration: Clinicaltrials.gov NCT04127799; https://clinicaltrials.gov/ct2/show/NCT04127799

(JMIR Mhealth Uhealth 2020;8(10):e22137) doi: 10.2196/22137

\section{KEYWORDS}

atrial fibrillation; integrative management; telemedicine; self-management; feasibility study 


\section{Introduction}

Atrial fibrillation is the most prevalent cardiac arrhythmia and has cumulatively been acknowledged as a major health care burden globally [1]. Despite the fact that atrial fibrillation is infrequent among young people $(<1 \%$ in individuals aged $<40$ years), its incidence dramatically increases with age, reaching up to $10 \%-17 \%$ in individuals above the age of 80 years $[1,2]$. The lifetime risk of atrial fibrillation is $21 \%-23 \%$ in women and $17 \%-26 \%$ in men [3,4]. Approximately 33.5 million individuals were suffering from atrial fibrillation in 2010 globally, which is predicted to double by 2050 owing to widespread population aging [5]. Additionally, atrial fibrillation is associated with a 5-fold increase in ischemic stroke risk and accounts for $15 \%-20 \%$ of all strokes [6,7]. Strokes arising from atrial fibrillation are more catastrophic and disabling than those of other etiologies, which has been described as an "atrial fibrillation-correlative stroke tsunami" [8].

Oral anticoagulants therapy can markedly reduce the risk of stroke by $64 \%$ and the risk of death by $26 \%$ in patients with atrial fibrillation [9]. However, the underuse or improper use of oral anticoagulants is fairly common in real-world clinical practice, even in the new era of nonvitamin $\mathrm{K}$ antagonist oral anticoagulants (NOACs), especially in many Asian countries [10-12]. In comparison with Europe (90.1\%) and North America $(78.3 \%)$, the reported usage rate of oral anticoagulants was notably lower in Asia (55.2\%) and well below the global average (79.9\%) [11]. Furthermore, $17.7 \%$ of high-risk patients were not anticoagulated (Europe $8.8 \%$; Asia 42.4\%), whereas $76.5 \%$ of low-risk patients were inappropriately anticoagulated [11]. In Asia, oral anticoagulant use varies from $21.0 \%$ in China (5.8\% for NOACs) to $89.7 \%$ in Japan [11].

The integrative management of atrial fibrillation patients is deemed to have the potential to improve the oral anticoagulant rate and patient prognosis, which comprises the following core elements: (1) patient-centeredness, (2) multidisciplinary teamwork, (3) utilization of intelligent technology, and (4) application of comprehensive strategies with access to all therapy options [13-15]. Additionally, the European Society of Cardiology developed an app to support the management of patients with atrial fibrillation [16]. To date, several preliminary studies have demonstrated the benefits of integrated atrial fibrillation care in reducing readmission rates [17], cardiovascular and all-cause mortality [17-20], and atrial fibrillation-associated health care expenditures [21]. However, a majority of prior studies have been dominated by nurses [17-19] with latent gaps in the better implementation of guidelines [22]. Additionally, these were mostly single-center studies covering a finite region or supported by a single management strategy such as a structured telephone follow up [23], web platform [16], or app [24].

To our knowledge, no subsistent program has integrated a mobile app, web platform, and intelligent health monitoring devices with cooperation among specialists, general practitioners, patients, and their caregivers to care and empower patients in disease self-management. There are scarce data on the implementation of such an integrated program to manage atrial fibrillation patients, particularly regarding its feasibility and safety. On the basis of our heart failure management program [25,26], we conducted the Hospital-Community-Family-Based Telemedicine (HCFT-AF) program incorporating the core elements mentioned above. The aim of this study was to ascertain the feasibility of the HCFT-AF program for implementation of integrated atrial fibrillation care.

\section{Methods}

\section{Study Design and Participants}

This single-arm, pre-post design study was part of the HCFT-AF program (ClinicalTrials.gov NCT04127799), which received ethics approval (2019093) from the Institutional Review Board of Northern Jiangsu People's Hospital [27]. Eligible patients (Textbox 1) were enrolled consecutively in November 2019 and were followed up for at least 4 months (Figure 1). All patients provided written informed consent before enrolling in the study. 
Textbox 1. Inclusion and exclusion criteria.

\section{Inclusion criteria}

- $\quad$ Aged $\geq 18$ years

- Meeting the diagnostic criteria for atrial fibrillation

- Understand the nature of the study, and agree to sign informed consent and continue follow up

\section{Exclusion criteria}

- Atrial fibrillation due to a reversible cause (eg, untreated hyperthyroidism, acute myocardial infarction, or acute myocarditis within 1 month)

- No recurrence of atrial fibrillation after surgical treatment

- Combined with other diseases with a life expectancy less than 1 year

- Severe liver and kidney disfunction: serum creatinine $>5.0 \mathrm{mg} / \mathrm{dL}$; alanine transaminase exceeds the reference value by more than 3 times $(>100$ $\mathrm{U} / \mathrm{L})$

- Systolic/diastolic blood pressure $\geq 180 / 110 \mathrm{mmHg}$, but can be enrolled after achieving blood pressure control

- Diagnosed or suspected blood system disease (except for mild to moderate anemia), leading to coagulopathy or combined with bleeding tendency

- Pregnant and lactating women

- Unable to use remote monitoring equipment (eg, depression, dementia)

- Participating in other treatment research or remote patient management programs

- Investigators considered that it is inappropriate to participate in the study

Figure 1. Flow diagram of the pilot study.

\section{Patients were assessed for eligibility $(n=96)$}

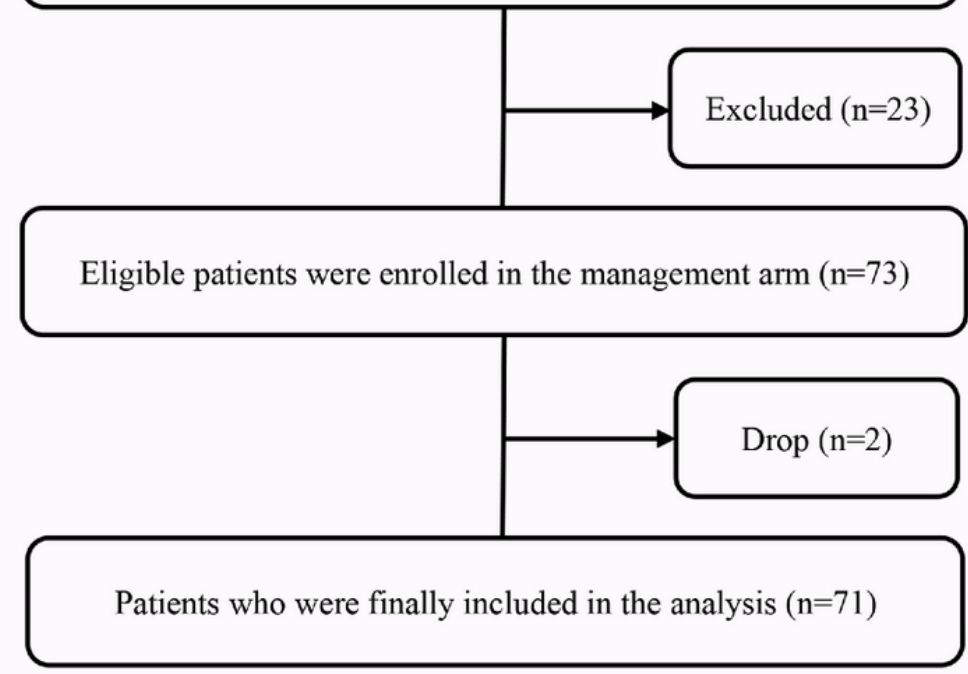

\section{Supportive System in the HCFT-AF Program}

\section{System Overview}

A user-friendly supportive system was developed to better deliver integrated atrial fibrillation management. In general, this system incorporates the following three major components: (1) a multifunctional service platform (Physio-Gate PG 2000, GETEMED AG), (2) a personal health data app (King OPTO-Electronic AG), and (3) a few health monitoring devices.

\section{Multifunctional Service Platform}

The multifunctional service platform [28] covers patients' data collection, storage, education, and audio-video portions. In our initial version, patients' data could only be collected manually, which was time-consuming, labor-intensive, and had a high error rate. In version 2.0 , the platform can automatically create a structured medical record via a document exported from the hospital information system. Additionally, data uploaded by participants through the app can be deposited on the platform. Abnormal values are coded with different colors: green denotes reduction, orange denotes moderate risk, red denotes high risk, 
and no color denotes normal or approximating the normal range. In this way, physicians can master patients' condition more comprehensively and rapidly. The online library on the platform provides multifaceted knowledge on atrial fibrillation (eg, guideline-based therapy, guidance for self-management). The platform is also equipped with a highly confidential audio-video system to protect patient privacy. In brief, this platform serves as a bridge for information interaction and resource sharing between all stakeholders in this program.

\section{Mobile App}

A user-friendly mobile app, available on both Android and iOS, was respectively developed for patients and physicians. The data obtained with access to an internet connection can be accessed offline, after the network is disconnected, while subsequent updates require connection to the network. The version for physicians assists them in better managing patients and allows them to observe and track the health status of patients more conveniently. Physicians can view the medical records of

Figure 2. Screenshots of the mobile app for patients.

\begin{tabular}{ll|l|}
\hline \multicolumn{1}{|c|}{ Data elements } \\
\hline Sign \\
Systolic pressure \\
Diastolic pressure \\
Resting heart rate \\
Arrhythmia \\
Weight
\end{tabular}

\section{Intelligent Health Monitoring Devices}

In addition to the ACT Plus automatic clotting time tester (Medtronic PLC, Minneapolis, MN, USA), some intelligent health monitoring devices are available in our program: a multicomponent monitor (blood pressure, oxyhemoglobin saturation, and electrocardiograph; TE-4000Y, Beijing Hailiying Medical Technology Ltd, Beijing, China) and a long-term wearable electrocardiograph monitor (BECG1200-A, Thoth Medical Technology Ltd, Suzhou, China) (see Multimedia Appendix 1). These health monitoring devices make remote monitoring, recording, and analysis of patient health status possible. patients in their charge. When patients upload data or seek remote consultation, their attending physicians will be reminded.

The patient version has the following major functions: medical record viewing, health-related data uploading, and remote consultation (Figure 2). This app enables patients to view their medical records documented by physicians, which is significant for those taking multiple drugs simultaneously. As an important part of self-management, patients can record and upload health-related data via the app, including daily recording of symptom changes, resting ventricular rate, rhythm, and blood pressure. Their attending physicians will then examine the data and provide corresponding suggestions. In addition, patients can communicate with physicians more conveniently with the remote consultation function. Bleeding caused by warfarin is partly due to unreasonable medication combinations, which can be avoided by timely communication with clinicians [29]. Furthermore, a reminder alert is sent automatically for forthcoming clinic appointments and a structured follow-up schedule is accessible in the app.

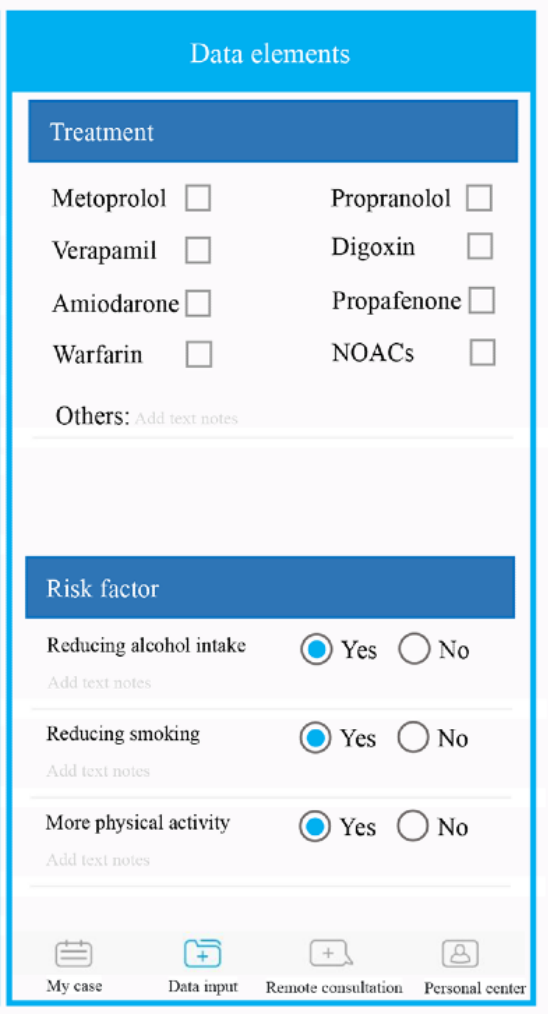

\section{Procedures}

In general, the intervention included three major elements: education, streamlined guideline-based therapy, and periodic follow up. The educational section mainly had two target audiences. The first was patients and their caregivers, incorporating the detriment and self-management of atrial fibrillation, use of supportive health monitoring devices, and other components. The second was general practitioners in communities, aiming to narrow the gap between physicians and guideline-based therapy.

Researchers introduced the study protocol to the eligible patients and their caregivers. In addition, for integrating the management 
group, research assistants helped to install the app, and provided instructions on use of the multifunctional service platform, app, and health monitoring devices. A complete medical record was established on the multifunctional service platform before the study officially started. Thereafter, patients were assigned to the community hospital closest to them for further follow up. Structured follow up was arranged once every 2-4 months after discharge, and related examinations were performed every 3-6 months or depending on the condition of patients. During periodic clinical visits, participants were encouraged to record and upload their health-related data via the app and to follow the educational program to improve their disease self-management ability. For patients who were at high risk of severe arrhythmia, some intelligent health monitoring devices were furnished to record and transfer health parameters remotely. Patients and their families could interact with their supervising general practitioners more conveniently via the app if needed.

The general practitioners in community hospitals checked the data submitted by the patients and identified abnormal health data in comparison with previous medical records. In such cases, they would give appropriate treatments or consult specialists at a regional central hospital according to the risk level of the patients. Patients can be transferred to the central hospital through a fast track if necessary. In addition to managing patients, community physicians can also access the latest guideline-based atrial fibrillation therapy through the multifunctional service platform.

Cardiologists of regional central hospitals performed remote ward rounds weekly for patients that were deemed to be complicated or difficult to handle via the dedicated audio-video system by general practitioners, and clinic visit schedules were adjusted according to the condition of the patient when necessary. For patients with complicated conditions, cardiologists would discuss the treatment schedule with neurologists, cardiac surgeons, and other specialists. Furthermore, specialists performed online video seminars regularly for general practitioners and patients, aiming to increase the capacity of general practitioners and compliance of patients to the standardized therapy.

\section{Outcomes and Instruments}

Patients' drug adherence was assessed via the Pharmacy Quality Alliance adherence measure [30] at baseline and at 4 months individually. Patients' lifestyles and behaviors associated with the occurrence and progress of atrial fibrillation were collected at baseline and 4 months through interviews with the purpose of evaluating changes in self-management. Additionally, the acceptability, feasibility, and usability of the HCFT-AF intervention for patients were measured via the Perceived Health Web Site Usability Questionnaire [31] at 4 months. This questionnaire consists of three separate portions that evaluate patient satisfaction (eg, "It is easy to find specific information"), ease of use (eg, "I found the HCFT-AF intervention easy to learn"), and usefulness (eg, "Using the HCFT-AF intervention will help me improve my knowledge about health"). All points are rated on a 1 to 7 scale. Responses were averaged for each element and across all points, with higher scores indicating better satisfaction, easier use, higher effectiveness, and greater overall usability of the intervention. The engagement of the HCFT-AF program was roughly estimated by the frequency of patients' account logins and the completion degree of the follow-up schedule. The patients' feedback with the intervention was obtained through self-reported questionnaires at the end of the study.

\section{Statistical Analysis}

Demographic traits of patients were collected and are presented as continuous or categorical variables. Continuous variables, verified for normality by the Kolmogorov-Smirnov test, are presented as means (SD) or median (IQR) as appropriate. In addition, the data were compared via a $t$ test or Mann-Whitney $U$ test, as appropriate. Categorical variables are reported as the absolute number and percentage, which were analyzed by the chi-square test or Fisher exact test. All statistical tests were two-tailed, and $P<.05$ was considered to indicate statistical significance. Statistical analyses were performed on GraphPad Prism version 8.00 for Windows (GraphPad Software, La Jolla, CA, USA).

\section{Results}

\section{Participant Characteristics}

A total of 73 eligible patients (mean age, 68.42 years; $52 \%$ male) were enrolled in this feasibility study in November 2019 with a median follow up of 132 days (IQR 125-138). Of the original cohort, 71 patients completed the 4-month follow up. Two patients dropped out after failing to complete regular clinical follow ups. Basic demographic data were collected at baseline (Table 1). Less than half of the qualified patients received anticoagulant therapy. Fifty-three physicians (mean age, 41.72 years; $58 \%$ were male) participated in the routine management of patients. Nearly half of the physicians $(25 / 53$, $47 \%$ ) had more than 10 years of work experience. About $30 \%$ $(16 / 53)$ of the physicians were specialists, including cardiologists $(20 \%, 11 / 53)$, neurologists $(6 \%, 3 / 53)$, and cardiac surgeons $(4 \%, 2 / 53)$.

During the study period, specialists from the regional central hospital conducted 34 online lectures and 168 remote ward rounds in total. In addition, general practitioners consulted the experts in the regional central hospital remotely 102 times. One patient with high-grade atrioventricular block detected by intelligent health monitoring devices was transferred to the regional central hospital via a fast track. Furthermore, 5 patients had bleeding gums and 2 had epistaxis; however, the anticoagulation treatment was not interrupted after appropriate treatment was given. No other relevant serious adverse events were reported. 
Table 1. Baseline characteristics of patients in the study $(\mathrm{N}=73)$.

\begin{tabular}{|c|c|}
\hline Characteristics & Value \\
\hline Age (years), mean (SD) & $68.42(10.25)$ \\
\hline Male, n (\%) & $38(52)$ \\
\hline \multicolumn{2}{|l|}{ Medical history, n (\%) } \\
\hline Hypertension & $37(51)$ \\
\hline Diabetes & $16(22)$ \\
\hline Congestive heart failure & $15(21)$ \\
\hline Previous stroke/TIA ${ }^{\mathrm{a}}$ & $10(14)$ \\
\hline Renal dysfunction & $6(8)$ \\
\hline Liver dysfunction & $4(6)$ \\
\hline Peripheral vascular disease & $4(6)$ \\
\hline \multicolumn{2}{|l|}{ Type of atrial fibrillation, $\mathrm{n}(\%)$} \\
\hline Paroxysmal & $35(48)$ \\
\hline Persistent & $28(38)$ \\
\hline Permanent & $10(14)$ \\
\hline \multicolumn{2}{|l|}{ Atrial fibrillation treatment, n (\%) } \\
\hline Beta-blocker & $34(47)$ \\
\hline Pharmacologic cardioversion & $15(21)$ \\
\hline Anticoagulant therapy ${ }^{b}$ & $28(38)$ \\
\hline Atrial fibrillation ablation & $8(11)$ \\
\hline $\mathrm{LAAO}^{\mathrm{c}}$ & $1(1)$ \\
\hline \multicolumn{2}{|l|}{ Anthropometric data, n (\%) } \\
\hline $\mathrm{BMI}\left(\mathrm{kg} / \mathrm{m}^{2}\right)$ & $23.15(5.49)$ \\
\hline Overweight $^{\mathrm{d}}$ & $21(29)$ \\
\hline Current drinker & $36(49)$ \\
\hline Current smoker & $28(38)$ \\
\hline \multicolumn{2}{|l|}{ Daily caregiver, $n(\%)$} \\
\hline Spouse or children & $62(85)$ \\
\hline Relative & $8(11)$ \\
\hline Others & $3(4)$ \\
\hline CHA2DS2-VASc ${ }^{\mathrm{e}}$ score, mean (SD) & $2.89(1.71)$ \\
\hline HAS-BLED ${ }^{\mathrm{f}}$ score, mean (SD) & $2.32(1.13)$ \\
\hline
\end{tabular}

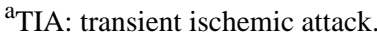

${ }^{\mathrm{b}}$ Anticoagulant therapy denotes receiving vitamin $\mathrm{K}$ antagonist or nonvitamin $\mathrm{K}$ antagonist oral anticoagulant.

${ }^{c}$ LAAO: left atrial appendage occlusion.

${ }^{\mathrm{d}}$ Overweight denotes $\mathrm{BMI} \geq 25 \mathrm{~kg} / \mathrm{m}^{2}$.

${ }^{\mathrm{e}} \mathrm{CHA}_{2} \mathrm{DS}_{2}$-VASc: congestive heart failure, hypertension, age $\geq 75$ (doubled), diabetes mellitus, prior stroke or transient ischemic attack (doubled), vascular disease, age 65-74, female gender.

${ }^{\mathrm{f}}$ HAS-BLED: hypertension, abnormal renal/liver function, stroke, bleeding history or predisposition, labile international normalized ratio, elderly, drugs/alcohol concomitantly.

\section{Predicted Drug Adherence to Long-Term Treatment}

Predicted drug adherence of patients significantly improved at 4 months $(P<.001)$ (Table 2). More than $90 \%$ of the indicated patients received anticoagulant therapy at 4 months, and none of them received antiplatelet therapy unless there was an additional indication. 
Table 2. Drug adherence, and amelioration in lifestyle and health behaviors.

\begin{tabular}{llll}
\hline Variable & Baseline (N=73) & 4 months (N=71) & $P$ value \\
\hline $\begin{array}{l}\text { Predicted adherence }{ }^{\text {a }} \text {, mean (SD) } \\
\text { Diet, } \mathbf{n}(\%)\end{array}$ & $6.57(2.76)$ & $1.45(1.47)$ & $<.001$ \\
$\quad$ Low-salt, low-fat diet & $31(42)$ & $43(61)$ & .04 \\
$\quad$ More fruits or vegetables intake & $18(25)$ & $54(76)$ & .009 \\
Healthy lifestyles, $\mathbf{n}(\%)$ & & $30(42)$ & .005 \\
$\quad$ Moderate physical activity & $16(22)$ & $52(73)$ & .04 \\
$\quad$ Quitting or reducing alcohol intake & $37(51)$ & $55(78)$ & $<.001$ \\
$\quad$ Quitting or reducing smoking & $45(62)$ & & $<.001$ \\
Self-monitoring, $\mathbf{n}(\%)$ & & $51(72)$ & $<.001$ \\
Blood pressure & $19(26)$ & $37(52)$ & $34(48)$ \\
$\quad$ Heart rate & $8(11)$ & $5(7)$ & \\
$\quad$ Rhythm & & & \\
\hline
\end{tabular}

${ }^{\mathrm{a}}$ Pharmacy Quality Alliance adherence measures were used to predict possible adherence problems at the following three levels: low risk (0), moderate risk (2-7), and high risk (8+); possible range $=0-36$.

${ }^{\mathrm{b}}$ Moderate physical activity $=150$ minutes/week of moderate-intensity exercise [32].

\section{Ameliorations in Lifestyles and Healthy Behaviors}

The healthy lifestyles and behaviors of patients improved to varying degrees after the 4-month HCFT-AF intervention (Table 2).

\section{Acceptability, Feasibility, and Usability of the HCFT-AF Intervention}

The majority of patients provided good feedback on the HCFT-AF intervention, especially related to its usefulness and satisfaction (Table 3). Cronbach $\alpha$ of the satisfaction, ease of use, usefulness, and overall scale was $.89, .85, .83$, and .90 , respectively. The 31 surveyed physicians ( 10 specialists and 21 general practitioners) also provided a positive appraisal on the program. All specialists agreed that they were liberated from simple primary repetitive work via the hierarchical management program, and could offer more comprehensive and individual care of patients in comparison with traditional outpatient visits. More than 90\% (19/21) of the general practitioners claimed that they had gained substantial professional knowledge and experience about atrial fibrillation from this program. They were also willing and able to provide atrial fibrillation patients with standardized guideline-based therapy.

Table 3. Acceptability, feasibility, and usability of patients with the Hospital-Community-Family-Based Telemedicine (HCFT-AF) intervention.

\begin{tabular}{lll}
\hline Category $^{\mathrm{a}}$ & Mean (SD) & Range \\
\hline Satisfaction & $5.21(1.43)$ & $2.45-7.00$ \\
Ease of use & $4.76(1.58)$ & $1.86-7.00$ \\
Usefulness & $5.45(1.40)$ & $3.12-7.00$ \\
Overall usability of the intervention & $5.11(1.52)$ & $2.68-7.00$ \\
\hline
\end{tabular}

${ }^{a}$ Scored on a scale of 1-7; higher scores indicate better satisfaction, easier use, higher effectiveness, and greater overall usability of the intervention.

\section{Engagement of the HCFT-AF Program}

Overall, 76\% (54/71) of the patients used the software or website more than once a week and accomplished clinic visits as scheduled. In addition, 70\% (50/71) of the patients uploaded health-related data periodically during the 4-month study period. It is worth mentioning that more than half $(56 \%, 40 / 71)$ of the patients could utilize the mobile app or website by themselves. Learning education materials, communicating with health care physicians, and viewing their own medication prescriptions were the three most frequently used functions.

\section{Discussion}

\section{Principal Results}

The HCFT-AF program integrates streamlined guideline-based therapy, sustaining education (for patients, their caregivers, and general practitioners), and patient self-management with family involvement via a multifunctional telemedicine platform (Figure 3). This prospective single-arm pre-post design pilot study aimed to assess the feasibility and safety of this program. Preliminary results show that patients and physicians have a high degree of satisfaction and participation. More importantly, the standardized therapy rate, drug adherence, and unhealthy 
lifestyles of patients were all ameliorated to varying degrees after a short-term intervention.

Figure 3. The Hospital-Community-Family-based Telemedicine Program to implement integrated atrial fibrillation care.

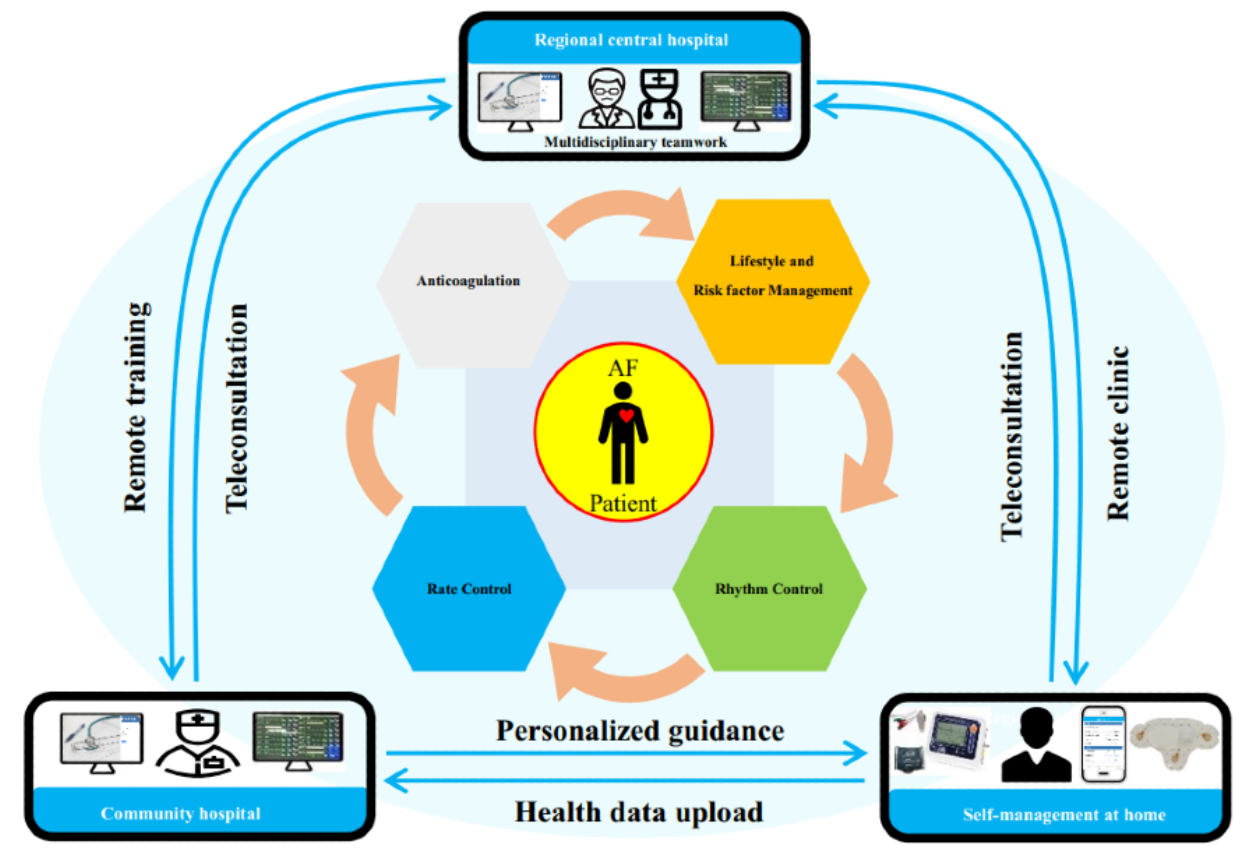

\section{Comparison With Prior Work}

Several large studies have contributed to disclosing the vital epidemiological traits of atrial fibrillation worldwide but also exposed the underuse of guideline-based standardized treatment, especially anticoagulation therapy $[1,5,10,11]$. Many factors account for this intractable plight. Warfarin's narrow treatment window, multiple drug and dietary interactions, and frequent laboratory monitoring are inherent defects contributing to the poor adherence to anticoagulant therapy [33]. The development of NOACs has overcome these drawbacks, but these drugs are still not covered by health insurance in most countries, including China, with a daily cost that is 160 to 200 times higher than that of warfarin, thereby hindering their long-term availability. In addition to the low drug-use rate, the discontinuation of medication is another problem that plagues clinicians. The RE-LY study reported that the rates of discontinuation at 1 and 2 years were $14.5 \%$ and $21.1 \%$ for dabigatran, and $10.2 \%$ and $16.6 \%$ for warfarin, respectively [34]; real-world data are even less optimistic [35].

Periodical clinical follow up is important to guarantee safe and effective anticoagulant therapy [17,36]. However, traditional outpatient visits mostly depend on the abnormality of patients' self-perception. Furthermore, the face-to-face outpatient visit mode prevents doctors from fully communicating with patients and providing effective out-of-hospital management. The HCFT-AF program furnishes patients with dual online and offline consistent follow up. Such facilitated medical visits can help to improve patient compliance with long-term therapy, especially for those with limited mobility or living in rural regions. More than three-quarters $(76 \%, 54 / 71)$ of patients accomplished medical visits as scheduled during this 4-month study.
Insufficient awareness of the hazard of atrial fibrillation and excessive worry of bleeding caused by anticoagulation therapy hinder nonspecialists from offering indicated patients with standardized therapy [29,37]. Guideline-based integrated atrial fibrillation management encompasses many aspects such as anticoagulant therapy, reversion to sinus rhythm, and controlling the ventricular rate, which are not easy to master for nonspecialists. However, this can also be simply streamlined in line with the Atrial fibrillation Better Care (ABC) pathway: "A" avoiding stroke with anticoagulants; "B" for better symptom amelioration with symptom-directed treatment via rate or rhythm control; and "C" for cardiovascular and comorbidity risk reduction, comprising lifestyle and risk factors management [38]. Promotion of such a strategy offers an opportunity to improve awareness and diagnosis, while empowering clinicians with straightforward decision-making steps that may align with the therapeutic regimen of generalists and specialists. Integrated management following the $\mathrm{ABC}$ pathway could reduce more than two-thirds of the all-cause deaths and half of the composite outcomes (eg, death, major bleeding, ischemic stroke, and myocardial infarction) after an average follow up of 6.2 (SD 3.5) years [39]. Moreover, it can reduce health-related costs significantly [40], demonstrating a clear benefit to optimize the management of patients with atrial fibrillation. However, the best strategy for implementation of such a program is still being explored. A majority of prior studies have been dominated by nurses [17-19] with latent gaps in the better implementation of guidelines [22]. Additionally, these were mostly single-center studies covering a finite region or supported by a single management strategy such as structured telephone follow up [23], web platform [16], or app [24]. The HCFT-AF program, supported by efficient infrastructures, may be an effective carrier for the implementation of integrated atrial fibrillation care. 
In addition, perceptions of patients and their caregivers about atrial fibrillation will influence their willingness and ability to obey the treatment recommendations [41]. Several studies have supported that better patient understanding is associated with improved health outcomes [42,43]. As holistic management of atrial fibrillation calls for patients to comply with long-term therapy and transform their unhealthy lifestyles, sometimes without a rapid visible benefit, it is important that they better understand their duties in the treatment. Clinicians are responsible for offering evidence-based therapy, whereas the compliance with the therapy is the responsibility of informed and autonomous patients, which is termed "shared accountability" [44]. A prior study demonstrated that a multifaceted educational intervention significantly improved the proportion of oral anticoagulants utilization, and therefore had the potential to ameliorate the outcome of stroke prevention [45]. The HCFT-AF program provides comprehensive education to patients and their caregivers on the risk factors, treatment, and self-management of atrial fibrillation. The app for patients and intelligent health monitoring devices empowers them to participate in their own disease management, thus aiding in improving adherence to long-term therapies.

Accumulating evidence demonstrates that amelioration in obesity [46], physical fitness [47], and hypertension [48], as well as other risk factors such as alcohol consumption, can reduce the atrial fibrillation burden, often to a degree that is not inferior to that of catheter ablation and other invasive methods [38]. Furthermore, interventions for additional risk factors can strengthen the benefits of disease-oriented therapies such as ablation. A recent scientific statement from the American Heart Association emphasized that lifestyle and risk factor management should be integrated as the fourth pillars in addition to the conventional triangle of atrial fibrillation management [38]. Some previous studies reported that the atrial fibrillation burden and severity can be improved through general lifestyle advice [46], weight intervention [46], or moderate exercise [49]. In general, it is currently well recognized that lifestyle and risk factors modification for atrial fibrillation should be managed as chronic diseases requiring multiple repeated interventions to bring forth long-term successful outcomes. Telemedicine contributing to lifestyle improvement has been confirmed in other domains of medicine [50-56]. On the one hand, telemedicine provides patients and their caregivers with sustaining education on the necessity of lifestyle alterations $[50,57]$. On the other hand, timely feedback from clinicians enhances patients' motivation to change their unhealthy lifestyles [52]. The HCFT-AF program encourages patients to record and upload their lifestyles through the app, followed by personalized advice from clinicians. Multiple repeated interventions may further motivate patients to change their unhealthy lifestyles.

With the launch of a large-scale atrial fibrillation screening program, the number of atrial fibrillation patients will increase exponentially [58]. Smartphones, computers, and internet-connected devices have become ubiquitous in modern life, which lay a foundation for integrating new methods and novel technologies to provide better care for more patients. A core team (eg, composed of cardiologists) supported by efficient infrastructures serves as an intermediary with other health care specialists, which may achieve optimal management. The overall process comprises a diagnostic assessment, initiation of appropriate guideline-based therapy, sustaining follow up, and education and empowerment of patients and their caregivers in disease self-management. Accordingly, stabilized and sufficiently managed patients can finish subsequent follow up by supported self-management at home or in the community online or offline. If necessary, the patient can be referred to the regional central hospital rapidly. Such integrated management based on telemedicine makes it possible to provide standardized treatment for more patients with limited medical resources.

\section{Limitations}

Some limitations of this study need to be discussed. First, given that this was a feasibility study aiming to lay the foundation for subsequent large-scale research, we adopted a convenience sample size without a formal power calculation. Second, previous similar studies have shown that our outcomes of interest showed no significant changes in the control group $[24,45,50]$; therefore, we conducted a single-arm study to ascertain the feasibility and safety of the HCFT-AF program. Hence, this study may not have been sufficiently powered to determine the relative benefits of the intervention. In terms of lifestyle management, we simply educated patients on the importance of lifestyle amelioration rather than providing them with a detailed weight loss or exercise plan. On the one hand, the improvement of lifestyle via education has been confirmed in several previous studies [45,50]. On the other hand, this mode will broaden the adaptability of our findings. Certainly, there is an additional benefit that some patients will attain from the protocol-driven lifestyle and risk factor management program [53]. Finally, the impact on the major clinical outcomes (eg, stroke, bleeding, death) will be summarized in our ongoing randomized controlled study, which was not the principle purpose of this study.

\section{Conclusions}

The findings from this pilot study highlight the major role of the HCFT-AF program in improving the standardized therapy rate, drug adherence, and lifestyles of patients with atrial fibrillation, while further enhancing the guideline adherence of clinicians, thus providing a theoretical basis for eventual clinical benefits. A multidisciplinary team, supported by efficient infrastructures, is conducive to narrow the gap between clinical practice and guidelines. The potential effectiveness of integrated management has already been confirmed; however, more studies are needed to ascertain the best strategy to implement the program, which will allow more patients to benefit from optimal evidence-based therapies. 


\section{Acknowledgments}

The authors wish to acknowledge all of the clinicians, research assistants, patients, and their caregivers for their participation in the study. This work was funded in part by grants from Jiangsu Provincial Science and Technology Department (project code: BL2013022).

\section{Authors' Contributions}

All authors contributed to the study and preparation of this manuscript. JJ and CD were responsible for collecting the data, performing the statistical analysis, and drafting the first version of the manuscript. GX was responsible for confirming the topic, study design, and further polishing of the manuscript. LX, SL, and ZY were responsible for the literature search and editing the manuscript. DY, SL, CK, BY, ZY, and SH were responsible for data collection, figures preparation, final editing, and preparation of the manuscript for submission. All authors read and approved the final manuscript.

\section{Conflicts of Interest}

None declared.

\section{Multimedia Appendix 1}

Supportive health monitoring devices.

[PNG File, 266 KB-Multimedia Appendix 1]

\section{References}

1. Rahman F, Kwan GF, Benjamin EJ. Global epidemiology of atrial fibrillation. Nat Rev Cardiol 2014 Nov;11(11):639-654. [doi: 10.1038/nrcardio.2014.118] [Medline: 25113750]

2. Krijthe BP, Kunst A, Benjamin EJ, Lip GYH, Franco OH, Hofman A, et al. Projections on the number of individuals with atrial fibrillation in the European Union, from 2000 to 2060. Eur Heart J 2013 Sep;34(35):2746-2751 [FREE Full text] [doi: 10.1093/eurheartj/eht280] [Medline: 23900699]

3. Guo Y, Tian Y, Wang H, Si Q, Wang Y, Lip GYH. Prevalence, incidence, and lifetime risk of atrial fibrillation in China: new insights into the global burden of atrial fibrillation. Chest 2015 Jan;147(1):109-119. [doi: 10.1378/chest.14-0321] [Medline: 24921459]

4. Lloyd-Jones DM, Wang TJ, Leip EP, Larson MG, Levy D, Vasan RS, et al. Lifetime risk for development of atrial fibrillation: the Framingham Heart Study. Circulation 2004 Aug 31;110(9):1042-1046. [doi: 10.1161/01.CIR.0000140263.20897.42] [Medline: 15313941]

5. Chugh SS, Havmoeller R, Narayanan K, Singh D, Rienstra M, Benjamin EJ, et al. Worldwide epidemiology of atrial fibrillation: a Global Burden of Disease 2010 Study. Circulation 2014 Feb 25;129(8):837-847 [FREE Full text] [doi: 10.1161/CIRCULATIONAHA.113.005119] [Medline: 24345399]

6. Wolf PA, Abbott RD, Kannel WB. Atrial fibrillation: a major contributor to stroke in the elderly. The Framingham Study. Arch Intern Med 1987 Sep;147(9):1561-1564. [Medline: 3632164]

7. Wolf PA, Abbott RD, Kannel WB. Atrial fibrillation as an independent risk factor for stroke: the Framingham Study. Stroke 1991 Aug;22(8):983-988. [doi: 10.1161/01.str.22.8.983] [Medline: 1866765]

8. López-López JA, Sterne JAC, Thom HHZ, Higgins JPT, Hingorani AD, Okoli GN, et al. Oral anticoagulants for prevention of stroke in atrial fibrillation: systematic review, network meta-analysis, and cost effectiveness analysis. BMJ 2017 Nov 28;359:j5058. [doi: 10.1136/bmj.j5058] [Medline: 29183961]

9. Hart RG, Pearce LA, Aguilar MI. Meta-analysis: antithrombotic therapy to prevent stroke in patients who have nonvalvular atrial fibrillation. Ann Intern Med 2007 Jun 19;146(12):857-867. [doi: 10.7326/0003-4819-146-12-200706190-00007] [Medline: 17577005$]$

10. Guo Y, Wang H, Tian Y, Wang Y, Lip GYH. Time Trends of Aspirin and Warfarin Use on Stroke and Bleeding Events in Chinese Patients With New-Onset Atrial Fibrillation. Chest 2015 Jul;148(1):62-72 [FREE Full text] [doi: 10.1378/chest.14-2018] [Medline: 25501045]

11. Mazurek M, Huisman MV, Rothman KJ, Paquette M, Teutsch C, Diener H, GLORIA-AF Investigators. Regional Differences in Antithrombotic Treatment for Atrial Fibrillation: Insights from the GLORIA-AF Phase II Registry. Thromb Haemost 2017 Dec;117(12):2376-2388 [FREE Full text] [doi: 10.1160/TH17-08-0555] [Medline: 29212125]

12. Wei Y, Xu J, Wu H, Zhou G, Chen S, Wang C, et al. Survey of Antithrombotic Treatment in Rural Patients (>60 years) with Atrial Fibrillation in East China. Sci Rep 2018 May 01;8(1):6830. [doi: 10.1038/s41598-018-24878-y] [Medline: 29717155]

13. Kirchhof P, Benussi S, Kotecha D, Ahlsson A, Atar D, Casadei B, et al. 2016 ESC Guidelines for the management of atrial fibrillation developed in collaboration with EACTS. Eur J Cardiothorac Surg 2016 Nov;50(5):e1-e88. [doi:

10.1093/ejcts/ezw313] [Medline: 27663299] 
14. NHFA CSANZ Atrial Fibrillation Guideline Working Group, Brieger D, Amerena J, Attia J, Bajorek B, Chan KH, et al. National Heart Foundation of Australia and the Cardiac Society of Australia and New Zealand: Australian Clinical Guidelines for the Diagnosis and Management of Atrial Fibrillation 2018. Heart Lung Circ 2018 Oct;27(10):1209-1266 [FREE Full text] [doi: 10.1016/j.hlc.2018.06.1043] [Medline: 30077228]

15. Lip GYH, Banerjee A, Boriani G, Chiang CE, Fargo R, Freedman B, et al. Antithrombotic Therapy for Atrial Fibrillation: CHEST Guideline and Expert Panel Report. Chest 2018 Nov;154(5):1121-1201. [doi: 10.1016/j.chest.2018.07.040] [Medline: 30144419]

16. Kotecha D, Chua WWL, Fabritz L, Hendriks J, Casadei B, Schotten U, European Society of Cardiology (ESC) Atrial Fibrillation Guidelines Taskforce, the CATCH ME consortiumthe European Heart Rhythm Association (EHRA). European Society of Cardiology smartphone and tablet applications for patients with atrial fibrillation and their health care providers. Europace 2018 Feb 01;20(2):225-233 [FREE Full text] [doi: 10.1093/europace/eux299] [Medline: 29040548]

17. Hendriks JML, Tieleman RG, Vrijhoef HJM, Wijtvliet P, Gallagher C, Prins MH, et al. Integrated specialized atrial fibrillation clinics reduce all-cause mortality: post hoc analysis of a randomized clinical trial. Europace 2019 Dec 01;21(12):1785-1792. [doi: 10.1093/europace/euz209] [Medline: 31390464]

18. Hendriks JML, de Wit R, Crijns HJGM, Vrijhoef HJM, Prins MH, Pisters R, et al. Nurse-led care vs. usual care for patients with atrial fibrillation: results of a randomized trial of integrated chronic care vs. routine clinical care in ambulatory patients with atrial fibrillation. Eur Heart J 2012 Nov;33(21):2692-2699. [doi: 10.1093/eurheartj/ehs071] [Medline: 22453654]

19. Carter L, Gardner M, Magee K, Fearon A, Morgulis I, Doucette S, et al. An Integrated Management Approach to Atrial Fibrillation. J Am Heart Assoc 2016 Jan 25;5(1):e002950. [doi: 10.1161/JAHA.115.002950] [Medline: 26811169]

20. Gallagher C, Elliott AD, Wong CX, Rangnekar G, Middeldorp ME, Mahajan R, et al. Integrated care in atrial fibrillation: a systematic review and meta-analysis. Heart 2017 Dec;103(24):1947-1953. [doi: 10.1136/heartjnl-2016-310952] [Medline: 28490616]

21. Saraswat MK, Carter L, Berrigan P, Sapp JL, Gray C, Fearon A, et al. Integrated Management Approach to Atrial Fibrillation Care: A Cost Utility Analysis. Can J Cardiol 2019 Sep;35(9):1142-1148. [doi: 10.1016/j.cjca.2019.04.016] [Medline: $\underline{31472812]}$

22. McKee G, Kerins M, Hamilton G, Hansen T, Hendriks J, Kletsiou E, et al. Barriers to ESC guideline implementation: results of a survey from the European Council on Cardiovascular Nursing and Allied Professions (CCNAP). Eur J Cardiovasc Nurs 2017 Dec;16(8):678-686. [doi: 10.1177/1474515117710097] [Medline: 28498092]

23. Li PWC, Yu DSF, Yan BBY. A nurse-coordinated integrated care model to support decision-making and self-care in patients with atrial fibrillation: A study protocol. J Adv Nurs 2019 Dec;75(12):3749-3757. [doi: 10.1111/jan.14164] [Medline: 31350778]

24. Guo Y, Chen Y, Lane DA, Liu L, Wang Y, Lip GYH. Mobile Health Technology for Atrial Fibrillation Management Integrating Decision Support, Education, and Patient Involvement: mAF App Trial. Am J Med 2017 Dec;130(12):1388-1396.e6 [FREE Full text] [doi: 10.1016/j.amjmed.2017.07.003] [Medline: 28847546]

25. Gu X, Zhu Y, Zhang Y, Sun L, Bao Z, Shen J, et al. Effect of telehealth interventions on major cardiovascular outcomes: a meta-analysis of randomized controlled trials. J Geriatr Cardiol 2017 Aug;14(8):501-508 [FREE Full text] [doi: 10.11909/j.issn.1671-5411.2017.08.013] [Medline: 29089966]

26. Guo X, Gu X, Jiang J, Li H, Duan R, Zhang Y, et al. A Hospital-Community-Family-Based Telehealth Program for Patients With Chronic Heart Failure: Single-Arm, Prospective Feasibility Study. JMIR Mhealth Uhealth 2019 Dec 13;7(12):e13229 [FREE Full text] [doi: 10.2196/13229] [Medline: 31833835]

27. Eysenbach G, CONSORT-EHEALTH Group. CONSORT-EHEALTH: improving and standardizing evaluation reports of Web-based and mobile health interventions. J Med Internet Res 2011 Dec 31;13(4):e126 [FREE Full text] [doi: 10.2196/jmir.1923] [Medline: 22209829]

28. International chronic cardiovascular disease management platform. URL: http://www.iccvd.com [accessed 2013-07-01]

29. Fanaroff AC, Ohman EM. Non-Vitamin K Antagonist Oral Anticoagulants in the Treatment of Atrial Fibrillation. Annu Rev Med 2019 Jan 27;70:61-75. [doi: 10.1146/annurev-med-042617-092334] [Medline: 30477393]

30. McHorney CA. The Adherence Estimator: a brief, proximal screener for patient propensity to adhere to prescription medications for chronic disease. Curr Med Res Opin 2009 Jan;25(1):215-238. [doi: 10.1185/03007990802619425] [Medline: 19210154]

31. Nahm E, Resnick B, Mills ME. Development and pilot-testing of the perceived health Web Site usability questionnaire (PHWSUQ) for older adults. Stud Health Technol Inform 2006;122:38-43. [Medline: 17102214]

32. Kraus WE, Powell KE, Haskell WL, Janz KF, Campbell WW, Jakicic JM, 2018 Physical Activity Guidelines Advisory Committee*. Physical Activity, All-Cause and Cardiovascular Mortality, and Cardiovascular Disease. Med Sci Sports Exerc 2019 Jun;51(6):1270-1281 [FREE Full text] [doi: 10.1249/MSS.0000000000001939] [Medline: 31095084]

33. Vinogradova Y, Coupland C, Hill T, Hippisley-Cox J. Risks and benefits of direct oral anticoagulants versus warfarin in a real world setting: cohort study in primary care. BMJ 2018 Jul 04;362:k2505. [doi: 10.1136/bmj.k2505] [Medline: 29973392] 
34. Connolly SJ, Ezekowitz MD, Yusuf S, Eikelboom J, Oldgren J, Parekh A, RE-LY Steering CommitteeInvestigators. Dabigatran versus warfarin in patients with atrial fibrillation. N Engl J Med 2009 Sep 17;361(12):1139-1151. [doi: 10.1056/NEJMoa0905561] [Medline: 19717844]

35. Salmasi S, Loewen PS, Tandun R, Andrade JG, De Vera MA. Adherence to oral anticoagulants among patients with atrial fibrillation: a systematic review and meta-analysis of observational studies. BMJ Open 2020 Apr 08;10(4):e034778. [doi: 10.1136/bmjopen-2019-034778] [Medline: 32273316]

36. Vinereanu D, Lopes RD, Bahit MC, Xavier D, Jiang J, Al-Khalidi HR, IMPACT-AF investigators. A multifaceted intervention to improve treatment with oral anticoagulants in atrial fibrillation (IMPACT-AF): an international, cluster-randomised trial. Lancet 2017 Oct 14;390(10104):1737-1746. [doi: 10.1016/S0140-6736(17)32165-7] [Medline: 28859942]

37. Raparelli V, Proietti M, Cangemi R, Lip GYH, Lane DA, Basili S. Adherence to oral anticoagulant therapy in patients with atrial fibrillation. Focus on non-vitamin K antagonist oral anticoagulants. Thromb Haemost 2017 Jan 26;117(2):209-218. [doi: 10.1160/TH16-10-0757] [Medline: 27831592]

38. Chung MK, Eckhardt LL, Chen LY, Ahmed HM, Gopinathannair R, Joglar JA, American Heart Association ElectrocardiographyArrhythmias CommitteeExercise, Cardiac Rehabilitation, Secondary Prevention Committee of the Council on Clinical Cardiology; Council on Arteriosclerosis, Thrombosis Vascular Biology; Council on CardiovascularStroke Nursing;Council on LifestyleCardiometabolic Health. Lifestyle and Risk Factor Modification for Reduction of Atrial Fibrillation: A Scientific Statement From the American Heart Association. Circulation 2020 Apr 21;141(16):e750-e772. [doi: 10.1161/CIR.0000000000000748] [Medline: $\underline{\text { 32148086] }}$

39. Yoon M, Yang P, Jang E, Yu HT, Kim T, Uhm J, et al. Improved Population-Based Clinical Outcomes of Patients with Atrial Fibrillation by Compliance with the Simple ABC (Atrial Fibrillation Better Care) Pathway for Integrated Care Management: A Nationwide Cohort Study. Thromb Haemost 2019 Oct;119(10):1695-1703. [doi: 10.1055/s-0039-1693516] [Medline: 31266082]

40. Pastori D, Farcomeni A, Pignatelli P, Violi F, Lip GY. ABC (Atrial fibrillation Better Care) Pathway and Healthcare Costs in Atrial Fibrillation: The ATHERO-AF Study. Am J Med 2019 Jul;132(7):856-861. [doi: 10.1016/j.amjmed.2019.01.003] [Medline: 30659810]

41. Clarkesmith DE, Lip GYH, Lane DA. Patients' experiences of atrial fibrillation and non-vitamin K antagonist oral anticoagulants (NOACs), and their educational needs: A qualitative study. Thromb Res 2017 May;153:19-27. [doi: 10.1016/j.thromres.2017.03.002] [Medline: 28314139]

42. Asnani MR, Quimby KR, Bennett NR, Francis DK. Interventions for patients and caregivers to improve knowledge of sickle cell disease and recognition of its related complications. Cochrane Database Syst Rev 2016 Oct 06;10:CD011175 [FREE Full text] [doi: 10.1002/14651858.CD011175.pub2] [Medline: 27711980]

43. Oddone EZ, Gierisch JM, Sanders LL, Fagerlin A, Sparks J, McCant F, et al. A Coaching by Telephone Intervention on Engaging Patients to Address Modifiable Cardiovascular Risk Factors: a Randomized Controlled Trial. J Gen Intern Med 2018 Sep;33(9):1487-1494. [doi: 10.1007/s11606-018-4398-6] [Medline: 29736750]

44. Peterson ED, Ho PM, Barton M, Beam C, Burgess LH, Casey DE, et al. ACC/AHA/AACVPR/AAFP/ANA concepts for clinician-patient shared accountability in performance measures: a report of the American College of Cardiology/American Heart Association Task Force on Performance Measures. Circulation 2014 Nov 25;130(22):1984-1994 [FREE Full text] [doi: 10.1161/CIR.0000000000000139] [Medline: 25366994]

45. Vinereanu D, Lopes RD, Bahit MC, Xavier D, Jiang J, Al-Khalidi HR, IMPACT-AF investigators. A multifaceted intervention to improve treatment with oral anticoagulants in atrial fibrillation (IMPACT-AF): an international, cluster-randomised trial. Lancet 2017 Oct 14;390(10104):1737-1746. [doi: 10.1016/S0140-6736(17)32165-7] [Medline: 28859942]

46. Abed HS, Wittert GA, Leong DP, Shirazi MG, Bahrami B, Middeldorp ME, et al. Effect of weight reduction and cardiometabolic risk factor management on symptom burden and severity in patients with atrial fibrillation: a randomized clinical trial. JAMA 2013 Nov 20;310(19):2050-2060. [doi: 10.1001/jama.2013.280521] [Medline: 24240932]

47. Pathak RK, Elliott A, Middeldorp ME, Meredith M, Mehta AB, Mahajan R, et al. Impact of CARDIOrespiratory FITness on Arrhythmia Recurrence in Obese Individuals With Atrial Fibrillation: The CARDIO-FIT Study. J Am Coll Cardiol 2015 Sep 01;66(9):985-996 [FREE Full text] [doi: 10.1016/j.jacc.2015.06.488] [Medline: 26113406]

48. Huxley RR, Lopez FL, Folsom AR, Agarwal SK, Loehr LR, Soliman EZ, et al. Absolute and attributable risks of atrial fibrillation in relation to optimal and borderline risk factors: the Atherosclerosis Risk in Communities (ARIC) study. Circulation 2011 Apr 12;123(14):1501-1508 [FREE Full text] [doi: 10.1161/CIRCULATIONAHA.110.009035] [Medline: 21444879]

49. Malmo V, Nes BM, Amundsen BH, Tjonna A, Stoylen A, Rossvoll O, et al. Aerobic Interval Training Reduces the Burden of Atrial Fibrillation in the Short Term: A Randomized Trial. Circulation 2016 Feb 02;133(5):466-473. [doi: 10.1161/CIRCULATIONAHA.115.018220] [Medline: 26733609]

50. Rubinstein A, Miranda JJ, Beratarrechea A, Diez-Canseco F, Kanter R, Gutierrez L, GISMAL group. Effectiveness of an mHealth intervention to improve the cardiometabolic profile of people with prehypertension in low-resource urban settings in Latin America: a randomised controlled trial. Lancet Diabetes Endocrinol 2016 Jan;4(1):52-63. [doi: 10.1016/S2213-8587(15)00381-2] [Medline: 26653067] 
51. Meeker D, Goldberg J, Kim KK, Peneva D, Campos HDO, Maclean R, et al. Patient Commitment to Health (PACT-Health) in the Heart Failure Population: A Focus Group Study of an Active Communication Framework for Patient-Centered Health Behavior Change. J Med Internet Res 2019 Aug 06;21(8):e12483 [FREE Full text] [doi: 10.2196/12483] [Medline: 31389339]

52. Joiner KL, Nam S, Whittemore R. Lifestyle interventions based on the diabetes prevention program delivered via eHealth: A systematic review and meta-analysis. Prev Med 2017 Jul;100:194-207 [FREE Full text] [doi: 10.1016/j.ypmed.2017.04.033] [Medline: 28456513]

53. Kliemann N, Croker H, Johnson F, Beeken RJ. Development of the Top Tips Habit-Based Weight Loss App and Preliminary Indications of Its Usage, Effectiveness, and Acceptability: Mixed-Methods Pilot Study. JMIR Mhealth Uhealth 2019 May 10;7(5):e12326 [FREE Full text] [doi: 10.2196/12326] [Medline: 31094352]

54. Weerahandi H, Paul S, Quintiliani LM, Chokshi S, Mann DM. A Mobile Health Coaching Intervention for Controlling Hypertension: Single-Arm Pilot Pre-Post Study. JMIR Form Res 2020 May 07;4(5):e13989 [FREE Full text] [doi: 10.2196/13989] [Medline: 32379049 ]

55. Peiris D, Wright L, News M, Rogers K, Redfern J, Chow C, et al. A Smartphone App to Assist Smoking Cessation Among Aboriginal Australians: Findings From a Pilot Randomized Controlled Trial. JMIR Mhealth Uhealth 2019 Apr 02;7(4):e12745 [FREE Full text] [doi: 10.2196/12745] [Medline: 30938691]

56. Simeon R, Dewidar O, Trawin J, Duench S, Manson H, Pardo Pardo J, et al. Behavior Change Techniques Included in Reports of Social Media Interventions for Promoting Health Behaviors in Adults: Content Analysis Within a Systematic Review. J Med Internet Res 2020 Jun 11;22(6):e16002 [FREE Full text] [doi: 10.2196/16002] [Medline: 32525482]

57. Ding H, Jayasena R, Chen SH, Maiorana A, Dowling A, Layland J, et al. The Effects of Telemonitoring on Patient Compliance With Self-Management Recommendations and Outcomes of the Innovative Telemonitoring Enhanced Care Program for Chronic Heart Failure: Randomized Controlled Trial. J Med Internet Res 2020 Jul 08;22(7):e17559 [FREE Full text] [doi: 10.2196/17559] [Medline: 32673222]

58. Perez MV, Mahaffey KW, Hedlin H, Rumsfeld JS, Garcia A, Ferris T, Apple Heart Study Investigators. Large-Scale Assessment of a Smartwatch to Identify Atrial Fibrillation. N Engl J Med 2019 Nov 14;381(20):1909-1917. [doi: 10.1056/NEJMoa1901183] [Medline: 31722151]

\title{
Abbreviations \\ ABC: Atrial fibrillation Better Care \\ HCFT-AF: Hospital-Community-Family-Based Telemedicine \\ NOAC: non-vitamin $\mathrm{K}$ antagonist oral anticoagulant
}

\author{
Edited by G Eysenbach; submitted 05.07.20; peer-reviewed by H Mehdizadeh, D Agarwal; comments to author 16.07.20; revised \\ version received 22.07.20; accepted 26.07.20; published 21.10.20 \\ Please cite as: \\ Jiang J, Gu X, Cheng CD, Li HX, Sun XL, Duan RY, Zhu Y, Sun L, Chen FK, Bao ZY, Zhang Y, Shen JH \\ The Hospital-Community-Family-Based Telemedicine (HCFT-AF) Program for Integrative Management of Patients With Atrial \\ Fibrillation: Pilot Feasibility Study \\ JMIR Mhealth Uhealth 2020;8(10):e22137 \\ URL: http://mhealth.jmir.org/2020/10/e22137/ \\ doi: $10.2196 / 22137$ \\ PMID: $\underline{3084588}$
}

(CJiang Jiang, Xiang Gu, Chen-Di Cheng, Hong-Xiao Li, Xiao-Lin Sun, Ruo-Yu Duan, Ye Zhu, Lei Sun, Fu-Kun Chen, Zheng-Yu Bao, Yi Zhang, Jian-Hua Shen. Originally published in JMIR mHealth and uHealth (http://mhealth.jmir.org), 21.10.2020. This is an open-access article distributed under the terms of the Creative Commons Attribution License (https://creativecommons.org/licenses/by/4.0/), which permits unrestricted use, distribution, and reproduction in any medium, provided the original work, first published in JMIR mHealth and uHealth, is properly cited. The complete bibliographic information, a link to the original publication on http://mhealth.jmir.org/, as well as this copyright and license information must be included. 